\title{
miR-27a-3p regulates proliferation and apoptosis of colon cancer cells by potentially targeting BTG1
}

\author{
$\mathrm{CHANG} \mathrm{SU}^{1 *}$, DONG-PING HUANG ${ }^{2 *}$, JIAN-WEN LIU ${ }^{3}$, WEI-YAN LIU ${ }^{1}$ and YI-OU CAO ${ }^{1}$ \\ ${ }^{1}$ Department of Surgery, Minhang Branch, Zhongshan Hospital, Fudan University, Shanghai 201199; \\ ${ }^{2}$ Department of Surgery, People's Hospital of Putuo District, Shanghai 200060; ${ }^{3}$ Department of Molecular and \\ Cellular Pharmacology, School of Pharmacy, East China University of Science and Technology, Shanghai 200237, P.R. China
}

Received June 21, 2018; Accepted May 13, 2019

DOI: $10.3892 / \mathrm{ol} .2019 .10629$

\begin{abstract}
RNA (miR/miRNA)-27a-3p has been reported to be abnormally expressed in various types of cancer, including colorectal cancer (CRC). B-cell translocation gene 1 (BTG1) has also been implicated with CRC. However, the association between miR-27a-3p and BTG1 in $\mathrm{CRC}$, to the best of our knowledge, has not been investigated. In order to assess whether miR-27a-3p is associated with CRC, reverse transcription-quantitative PCR was performed on 20 paired CRC and paracancerous tissues for miRNA analysis. For the screening and validation of miR-27a-3p expression in colon cancer, several colon cancer cell lines (HCT-116, HCT8, SW480, HT29, LOVO and Caco2) and the normal colorectal epithelial cell line NCM460 were examined. The highest expression levels of miR-27a-3p were detected in the HCT-116, which was selected for further experimentation. The HCT-116 cells were divided into control, miR-27a-3p mimic and inhibitor groups, and cell proliferation was tested using an MTT assay. Additionally, miR-27a-3p inhibitor/mimic or BTG1 plasmid were transfected into the HCT-116 cells, and flow cytometry was performed to analyze cell cycle distributions. TUNEL analysis was performed to detect apoptosis. Protein levels of factors in the downstream signaling pathway mediated by miR-27a-3p [ERK/mitogen-activated extracellular signal-regulated kinase $(\mathrm{MEK})]$ were detected. miR-27a-3p was revealed to be overexpressed in human CRC tissues and colon cancer cell lines. Knockdown of miR-27a-3p
\end{abstract}

Correspondence to: Dr Wei-Yan Liu or Dr Yi-Ou Cao, Department of Surgery, Minhang Branch, Zhongshan Hospital, Fudan University, 170 Xinsong Road, Shanghai 201199, P.R. China

E-mail: 18918169211@189.cn

E-mail: yioucao_doctor@126.com

*Contributed equally

Abbreviations: BTG1, B-cell translocation gene 1; CRC, colorectal cancer; MEK, mitogen-activated extracellular signal-regulated kinase; miR-27a-3p, microRNA 27a-3p

Key words: microRNA, B-cell translocation gene 1, colorectal cancer suppressed proliferation of HCT-116 cells and apoptosis was increased. It further markedly upregulated expression levels of BTG1 and inhibited activation of proteins of the ERK/MEK signaling pathway. In addition, overexpression of BTG1 in HCT-116 cells triggered $G_{1} / S$ phase cell cycle arrest and increased apoptosis via the ERK/MEK signaling pathway. In conclusion, the present study demonstrated that the effects of miR-27a-3p on colon cancer cell proliferation and apoptosis were similar to those of the tumor suppressor gene BTG1. The miR-27a-3p/BTG1 axis may have potential implications for diagnostic and therapeutic approaches in CRC.

\section{Introduction}

Colorectal cancer (CRC) is one of the most common malignant tumors worldwide (1). At present, the main treatments for CRC are surgery, radio- and chemotherapy (2). In China, CRC is a serious health problem due to its high rate of mortality, which represented the third highest cancer-associated mortality rate nationally in 2012 (3). Additionally, the mortality rate of CRC in China was 4-8 times higher than that in Europe and America in 2012 (4). Associated treatments and the prognosis for patients with CRC are poor. Advanced CRC is usually associated with invasion and metastasis of tumor cells and distant organ metastases, making diagnosis more difficult and greatly increasing the difficulty of treatment (5-7).

microRNAs (miRNAs/miRs) are a widely studied type of non-coding RNA and have been found to be the closely associated with the pathogenesis and efficacy of treatment of cancer (8). Numerous miRNAs have been demonstrated to serve important roles in the growth, differentiation and apoptosis of cancer cells (9). Alterations in the expression levels and functions of specific miRNAs may serve a key role in the genesis of diverse cancer types (10-14). Our previous study demonstrated that miR-27a-3p promoted gastric cancer cell proliferation in vitro as well as tumor growth in vivo (15). miR-27a has further been identified to act as an oncogene in MGC803 cells and knockdown of miR-27a inhibits cell growth and was determined to be dose-dependent (16). Certain studies have demonstrated that overexpression of miR-27a-3p significantly promotes growth of cancer cells in glioma (17), hepatocellular carcinoma (18), esophageal cancer (19), renal cell carcinoma (20) and nasopharyngeal carcinoma (21). 
However, the role of miR-27a-3p in CRC and the underlying mechanisms are not well defined.

B-cell translocation gene (BTG)1, BTG2, BTG3, BTG4, transducer of ERBB2 and transducer of ERBB2 2 belong to the BTG family. As tumor suppressors, these proteins suppress cell proliferation and cell cycle progression, and induce differentiation $(22,23)$. In particular, BTG1 has been reported to regulate cell cycle progression in a variety of cells, including breast cancer (24) and renal cell carcinoma cells (25) and has been suggested to be a potential therapeutic target (26-30). BTG1 expression is highest in the $\mathrm{G}_{0} / \mathrm{G}_{1}$ phases of the cell cycle and suppresses the progression of cells through $\mathrm{G}_{1}$ phase (31). While BTG1 exhibits nuclear localization, associated signals enable it to undergo nucleo-cytoplasmic shuttling (32). Notably, BTG1 has been reported to increase and enhance antisense Bcl-2-induced cytotoxicity in MCF-7 and MDA-MB-231 breast cancer cells, and leukemia cell lines $(33,34)$. It has been reported previously that BTG1 inhibits the proliferation, migration and invasion of gastric cancer cells $(35,36)$, and is positively associated with increased expression of cyclin D1 and Bax, also known as anti-tumor protein (37). Overexpression of BTG1 serves an important role in CRC. Specifically, BTG1 expression reverses the aggressive phenotype and may be a candidate for gene therapy in CRC (38).

In the present study, miR-27a-3p was demonstrated to be overexpressed in human CRC tissues and colon cancer cell lines. Furthermore, the anti-proliferative gene BTG1 was predicted to be a direct target of miR-27a-3p. Therefore, the present study aimed to explore the association between miR-27a-3p and tumor growth, apoptosis, cell cycle distribution and the Ras/mitogen-activated extracellular signal-regulated kinase (MEK)/ERK signaling pathway. In summary, the miR-27a-3p/BTG1 axis could have potential implications for diagnostic and therapeutic approaches in CRC.

\section{Materials and methods}

Tissues. A total of 20 paired samples of human CRC and matched normal tissues were collected at Minhang Hospital (Affiliated to Fudan University) between December 2016 and February 2017. There were 13 males and 7 females, aged 38-62 years, included in the present study. The surgical procedures performed to obtain the tissues were laparoscopic radical resection of colorectal cancer. The lesion was considered to be normal tissue at a margin $>5 \mathrm{~cm}$ from the edge of the tumor. The samples were stored in liquid nitrogen following collection during surgery and were subsequently stored at $-80^{\circ} \mathrm{C}$. The use of these tissues was approved by the Institutional Review Board of Minhang Branch, Zhongshan Hospital and Fudan University Shanghai Cancer Center, and signed informed consent was obtained from all participants.

Plasmid construction. The homo sapiens-miR-27a (hsa-miR-27a) expression vector pEGFP-C1-miR-27a (+), the hsa-miR-27a competitive inhibitor vector pEGFP-C1-miR-27a (-) and the vector pEGFP-C1 were obtained from the State Key Laboratory of Bioreactor Engineering and Shanghai Key Laboratory of New Drug Design, School of Pharmacy, East China University of Science and Technology. The hsa-miR-27a expression vector pEGFP-C1-miR-27a (+) contains primary-miR-27a and some of its flanking sequences (33). The sequences of the has-miR-27a were: Forward, 5'-CCG CTCGAGACTGGCTGCTAGGAAGGTG-3' and reverse, 5'-GCGAATTCT TGCTGTAGCCTCCTTGTC-3'. The hsa-miR-27a competitive inhibitor vector pEGFP-C1-miR-27a $(-)$ was designed as a sponge of miR-27a with repeated binding sites complementary cloned into the pEGFP-C1 vector. The sequences of the miR-27a sponge were: Forward, 5'-CCCAAG CTTACTGTGAAACTGTGAAACGTGAAACTGTGAAAC TGTGAAACTGTGAATCTAGAGC-3' and reverse, 5'-GCT CTAGATTTCACAGTTTCACAGTTTCACAGTTTCACA

GTTTCACAGTAAGCTTGGG-3'. The construction of plasmids and respective sequences were performed as described previously (14). DNA was extracted from HCT-116 cells using TRIzol reagent (Invitrogen; Thermo Fisher Scientific, Inc.) and the coding region of BTG1 cDNA was amplified by PCR using $2 \mathrm{X}$ Hieff $^{\mathrm{TM}}$ PCR Master mix (Yeasen Biotech Co., Ltd.) according to the manufacturer's protocol. The thermocycling conditions were: $95^{\circ} \mathrm{C}$ for $1 \mathrm{~min}$; followed by 35 cycles of $62^{\circ} \mathrm{C}$ for $50 \mathrm{sec}, 94^{\circ} \mathrm{C}$ for $30 \mathrm{sec}, 60^{\circ} \mathrm{C}$ for $50 \mathrm{sec}$ and $72^{\circ} \mathrm{C}$ for $35 \mathrm{sec}$; and final extension at $72^{\circ} \mathrm{C}$ for $10 \mathrm{~min}$. PCR products were purified from the agarose gel using a gel purification kit (Promega Corporation) and were ligated to empty pcDNA3.1 vector at a 3:1 ratio at $4^{\circ} \mathrm{C}$ for $16 \mathrm{~h}$. Recombinant plasmids were then transferred to E. coli JM109 competent cells (cat. no. 9052; Takara Bio, Inc.). These cells were normally stored at $-80^{\circ} \mathrm{C}$. Prior to use, the E. coli JM109 competent cells were thawed on ice, and the pcDNA3.1 plasmid was mixed with the competent state at a ratio of 1:100, placed on ice for $30 \mathrm{~min}$, then placed at $42^{\circ} \mathrm{C}$ for $60-90 \mathrm{sec}$, incubated for $2-3 \mathrm{~min}$ and diluted in LB medium (Hangzhou Baisi Biotechnology Co., Ltd.). An appropriate amount of mixed solution was applied, and subsequently E.coli were cultured overnight in LB medium-containing plates with $1 \%$ ampicillin (Beijing Solarbio Science \& Technology Co., Ltd.) for amplification in a normal environment at $37^{\circ} \mathrm{C}$. Specific primers were designed by PrimerPremier 6.0 (Premier Biosoft International). The primer sequences were: Forward, 5'-GGAATTCATGCATCC CTTCTACACCCGG-3' and reverse, 5'-CGACGCGTTTAA CCTGATACAGTCATCAT-3'. Purified pcDNA-BTG1 recombinant plasmids were treated with $E c o \mathrm{RI}+X h o \mathrm{I}$ restriction enzymes (Promega Corporation) at $37^{\circ} \mathrm{C}$ for $4 \mathrm{~h}$. Digested products were separated using $1.5 \%$ agarose gel electrophoresis with ethidium bromide. DNA bands were identified by UV transilluminator (FR-200A; Shanghai Furi Science \& Technology Co., Ltd.). Purified recombinant plasmids ( $1 \mu \mathrm{g} / \mu \mathrm{l}$; A260/A280=1.8) were used to transfect cultured cells.

Cell culture and transfection. The human colon cancer cell lines HCT-116, HCT8, SW480, HT29, LOVO and Caco2 and the normal colorectal epithelial NCM460 cell line were purchased from the Type Culture Collection of the Chinese Academy of Sciences. All cell lines were cultured in DMEM (Gibco; Thermo Fisher Scientific, Inc.) supplemented with 10\% FBS (Gibco; Thermo Fisher Scientific, Inc.) containing $100 \mathrm{U} / \mathrm{ml}$ penicillin and $100 \mathrm{U} / \mathrm{ml}$ streptomycin (Thermo Fisher Scientific, Inc.) with $5 \% \mathrm{CO}_{2}$ at $37^{\circ} \mathrm{C}$ in a humidified environment. Cell transfection was performed using Lipofectamine ${ }^{\circledR}$ 3000 reagent (Invitrogen; Thermo Fisher Scientific, Inc.) according to the manufacturer's protocol. In brief, cultured 
cells were seeded into 6 -well plates $\left(5 \times 10^{5}\right.$ cells/well). Then, $5 \mu \mathrm{g}$ miR-27 mimic or $5 \mu \mathrm{g}$ miR-27 inhibitor and $10 \mathrm{ml}$ P3000 ${ }^{\mathrm{TM}}$ (Invitrogen; Thermo Fisher Scientific, Inc.) reagent were dissolved in $120 \mu \mathrm{l}$ DMEM each. Following incubation at room temperature for $20 \mathrm{~min}$, both miRNA and P3000 ${ }^{\mathrm{TM}}$ reagent were slowly added to cultured HCT-116 cells. After $24 \mathrm{~h}$ of incubation at $37^{\circ} \mathrm{C}$, the culture medium was changed. The control (no miRNA transfection) and empty (transfected with empty pEGFP-C1) group transfections were performed in parallel. Transfection efficiency was determined by reverse transcription-quantitative PCR (RT-qPCR) after $48 \mathrm{~h}$. Additional subsequent experiments were performed $48 \mathrm{~h}$ after the cells were transfected.

$R N A$ extraction and $R T-q P C R$. Total RNA was extracted from HCT-116 cells using TRIzol reagent (Invitrogen; Thermo Fisher Scientific, Inc.). Isolated miRNAs were reverse transcribed using TransScript miRNA First-Strand cDNA Synthesis SuperMix (Beijing Transgen Biotech Co., Ltd.). Briefly, $5 \mu$ l total RNA, $1 \mu$ 1 TransScript ${ }^{\circledR}$ miRNA RT Enzyme mix (Beijing Transgen Biotech Co., Ltd.), $10 \mu 1$ 2X TS miRNA Reaction mix (Beijing Transgen Biotech Co., Ltd.) and $4 \mu \mathrm{l}$ RNase-free water were mixed according to the manufacturer's instructions and incubated for $1 \mathrm{~h}$ at $37^{\circ} \mathrm{C}$, followed by incubation for $5 \mathrm{sec}$ at $85^{\circ} \mathrm{C}$. Subsequently, $0.2 \mu \mathrm{M}$ forward primer and $10 \mu 12 \mathrm{X}$ TransScript ${ }^{\circledR}$ Tip/Top Green qPCR SuperMix (Beijing Transgen Biotech Co., Ltd.) were mixed. The thermocycling conditions were: $94^{\circ} \mathrm{C}$ for $30 \mathrm{sec}$; followed by 45 cycles of $94^{\circ} \mathrm{C}$ for $5 \mathrm{sec}, 60^{\circ} \mathrm{C}$ for $15 \mathrm{sec}$ and $72^{\circ} \mathrm{C}$ for $15 \mathrm{sec}$; dissociation stage. The primer sequence for miR-27a-3p was 5'-TTCACAGTGGCTAAGTTCCGC-3'. mRNA was reverse transcribed with TransScript One-Step gDNA Removal and cDNA Synthesis SuperMix (Beijing Transgen Biotech Co., Ltd.). qPCR was performed according to the manufacturer's protocol of the TransScript Top Green qPCR SuperMix (Beijing Transgen Biotech Co., Ltd.) using an iCycler thermal cycler (Bio-Rad Laboratories, Inc.). The thermocycling conditions were: $94^{\circ} \mathrm{C}$ for $30 \mathrm{sec}$; followed by 40 cycles of $94^{\circ} \mathrm{C}$ for $5 \mathrm{sec}, 60^{\circ} \mathrm{C}$ for $15 \mathrm{sec}$ and $72^{\circ} \mathrm{C}$ for $10 \mathrm{sec}$; return to room temperature. The comparative cycle threshold method $\left(2^{-\Delta \Delta C q}\right)$ (39) was used to conduct the relative quantification of target genes and miRNAs (10). Levels of miRNA and mRNA were normalized against U6 snRNA and GAPDH, respectively. The primer sequences were: BTG1 forward, 5'-AGC TGAACCTGTATCTGCGG-3' and reverse, 5'-GAATTCCTG GTGCCAAAGGC-3'; U6 snRNA forward, 5'-ATTGGAACG ATACAGAGAAGATT-3' and reverse, 5'-GGAACGCTTCAC GAATTTG-3'; and GAPDH forward, 5'-GGTGAAGGTCGG AGTCAACG-3' and reverse, 5'-CAAAGTTGTCATGGA-3'. Transfection efficiency was determined by RT-qPCR.

Western blot analysis. RIPA lysis buffer (Beyotime Institute of Biotechnology) was used for cell lysis, the protein concentration was determined using a bicinchoninic acid assay (Thermo Fisher Scientific, Inc.) and 10\% SDS-PAGE was used to separate cellular proteins (50 $\mu \mathrm{g} /$ lane). Subsequently, protein was transferred to a $0.45 \mu \mathrm{m}$ PVDF filter at $200 \mathrm{~V}$ for $2 \mathrm{~h}$. The subsequent western blot analysis was carried out as described previously (38). Following blocking in 3\% BSA (A8020; Beijing Solarbio Science \& Technology) for $2 \mathrm{~h}$ at room temperature, membranes were incubated with appropriate primary antibodies in dilution buffer (3\% BSA; 1:1,000 dilution) overnight at $4^{\circ} \mathrm{C}$. $\beta$-actin was used as a loading control. Membranes were washed with TBS with $0.1 \%$ Tween-20 and incubated with horseradish peroxidase-conjugated secondary antibodies (cat. nos. 111-035-003 and 115-035-003; Jackson ImmunoResearch Laboratories, Inc.) at a dilution of 1:2,000 in $3 \% \mathrm{BSA}$ for $3 \mathrm{~h}$ at room temperature. Protein expression was assessed by enhanced chemiluminescence (cat. no. D3030L1260; Shanghai Life iLab Biological Technology Co., Ltd.) and exposure to chemiluminescent film. LabWorks ${ }^{\mathrm{TM}}$ Image Acquisition (version 4.0; UVP, LLC) was used.

Antibodies used in the present study, including anti-MEK (cat. no. 4694), anti-ERK (cat. no. 9102), anti-p-ERK (cat. no. 4370), anti-Ras (cat. no. 3965), anti-cyclin D1 (cat. no. 2922), anti-cyclin E1 (cat. no. 4129), anti-cleaved caspase-3 (cat. no. 9661), anti-cleaved poly(ADP-ribose) polymerase 1 (PARP1; cat. no. 5625) and anti- $\beta$-actin (cat. no. 3700), were purchased from Cell Signaling Technology, Inc. The anti-uncleaved caspase-3 (cat. no. ab13847) and anti-c-Myc (cat. no. ab32072) antibodies were purchased from Abcam. The antibody against BTG1 was purchased from ProteinTech Group, Inc. (cat. no. 14879-1-AP). The anti-p-MEK-1 (cat. no. sc-101733) antibody was purchased from Santa Cruz Biotechnology, Inc.

Proliferation and clone formation assays. Using the MTT method, the proliferation of HCT-116 cells transfected with mimics/inhibitor was assessed after 5 days of transfection. Cultured cells were seed into 96 -well plates $\left(1 \times 10^{4}\right.$ cells/well), and after 0, 24, 48 and $72 \mathrm{~h}, 20 \mu \mathrm{l}$ MTT solution $(5 \mu \mathrm{g} / \mathrm{ml}$; Sigma-Aldrich; Merck KGaA) was added to each well and the plate was further incubated at $37^{\circ} \mathrm{C}$ for $4 \mathrm{~h}$. Subsequently, the medium was aspirated and the wells were washed with PBS, allowed to dry for $\sim 2 \mathrm{~h}$ and $200 \mu \mathrm{l}$ DMSO (Sigma-Aldrich; Merck KGaA) was added to each well. The optical density was measured at 492 and $630 \mathrm{~nm}$ wavelength. Clone formation assays were performed as described previously (15).

miR-27a-3p potential target gene prediction. miRbase (version 20.0; http://www.mirbase.org/) was used to find the miRNA sequence. Subsequently, TargetMiner (https://www.isical. ac.in/ bioinfo_miu/TargetMiner.html), PicTar (https://pictar. mdc-berlin.de/cgi-bin/PicTar_vertebrate.cgi) (40) and TargetScan (version 7.1; www.targetscan.org) were used to predict the potential target genes of miR-27a-3p, and the intersection of the results was the target sequence.

Flow cytometry analysis. A Cell Cycle Assay kit (cat. no. FXP0211-200; 4A Biotech Co., Ltd.) was used according to the manufacturer's protocols and cell cycle distribution was analyzed by flow cytometry using a Fluorescence-activated Cell Sorting Vantage cytometer (BD Biosciences). In brief, the cells were harvested and fixed in ice-cold $70 \%$ (v/v) ethanol for $24 \mathrm{~h}$ at $4^{\circ} \mathrm{C}$. The cell pellet was collected by centrifugation at $500 \mathrm{x} \mathrm{g}$ for $10 \mathrm{~min}$ at $4^{\circ} \mathrm{C}$, resuspended in PBS, and stained with a mixture of RNase $(10 \mu \mathrm{g} / \mathrm{ml})$ and propidium iodide $(50 \mu \mathrm{g} / \mathrm{ml})$ in sodium citrate containing $0.5 \%$ Triton $\mathrm{X}-100$ for $20 \mathrm{~min}$ in the dark at room temperature. The percentages of cells in the different cell cycle phases were analyzed 
using WinMDI software (version 2.8; K. Trotter, The Scripps Research Institute, La Jolla, CA, USA).

Cells $\left(1 \times 10^{5}\right)$ were stained with the FITC Annexin-V Apoptosis Detection kit (R\&D Systems, Inc.) according to the manufacturer's protocol. Briefly, cells from cultures were collected, washed with cold PBS, and then stained with Annexin-V-FITC $(0.25 \mu \mathrm{g} / \mathrm{ml})$ and propidium iodide for $15 \mathrm{~min}$ at room temperature in the dark. The stained cells were then analyzed by flow cytometry, acquiring $1 \times 10^{5}$ events gated according to a large gate established on cell forward and side scatters within $30 \mathrm{~min}$ of staining. The apoptotic cell ratio was analyzed by flow cytometry using a fluorescence-activated cell sorting vantage cytometer (BD Biosciences). FlowJo version 10.5.0 software (FlowJo LLC) was used for analysis.

TUNEL analysis. Cells $\left(1 \times 10^{5}\right)$ were plated in 6-well culture plates containing gelatin-coated cover slips. Adherent cells were transfected with mimics or inhibitor of miR-27a-3p and pcDNA-BTG1 for $48 \mathrm{~h}$. Cells in the control group were not transfected. Treated cells and control cells were stained using a TUNEL FITC Apoptosis Detection kit (cat. no. C1088; Beyotime Institute of Biotechnology) according to the manufacturer's protocols. In brief, $1 \times 10^{5}$ cells were seeded on 6-well culture plates. Cells were washed with PBS for 5 min three times and fixed in 4\% paraformaldehyde (cat. no. AR1069; Wuhan Boster Biological Technology, Ltd.) at $4^{\circ} \mathrm{C}$ for $20 \mathrm{~min}$. The cells were incubated with the TUNEL enzyme for $60 \mathrm{~min}$ at $3^{\circ} \mathrm{C}$. Finally, the fluorescent reaction was counterstained with DAPI (1:1,000 in PBS; Sigma-Aldrich; Merck KGaA) to dye the nucleus for $10 \mathrm{~min}$ at room temperature. Antifade mounting medium (cat. no. P0126; Beyotime Institute of Biotechnology) was used. Images from four fields of view were captured using a fluorescence microscope (magnification, x20; DMI3000B; Leica Microsystems, Inc.).

Statistical analysis. Data are presented as the mean \pm SD. A Kruskal-Wallis-Test was performed to evaluate the significance of differences between the clinical tumor and normal samples, using a Steel Dwass post hoc test. Other data were analyzed using one-way ANOVA with a Tukey's HSD post hoc test. $\mathrm{P}<0.05$ was considered to indicate a statistically significant difference, and $\mathrm{P}<0.01$ was considered to indicate a statistically highly significant difference. Analysis was performed using Student's t-test. All data were representative of an average of three independent experiments. All statistical analyses were performed using GraphPad Prism 5.0 software (GraphPad Software, Inc.).

\section{Results}

miR-27a-3p is overexpressed in CRC tissues and colon cancer cells. To determine the expression levels of miR-27a-3p, expression levels in 20 paired CRC and normal tissues were assessed by RT-qPCR. Compared with in the corresponding non-tumor samples, the expression of miR-27a-3p was markedly increased in the CRC tissues, with a fold-change $>2.0$ (Fig. 1A and B). In addition, consistent with the results for the clinical CRC samples, expression levels of miR-27a-3p were identified to be markedly upregulated in colon cancer cell lines (HCT-116, HCT8, SW480, HT29, LOVO and Caco2) compared with in the
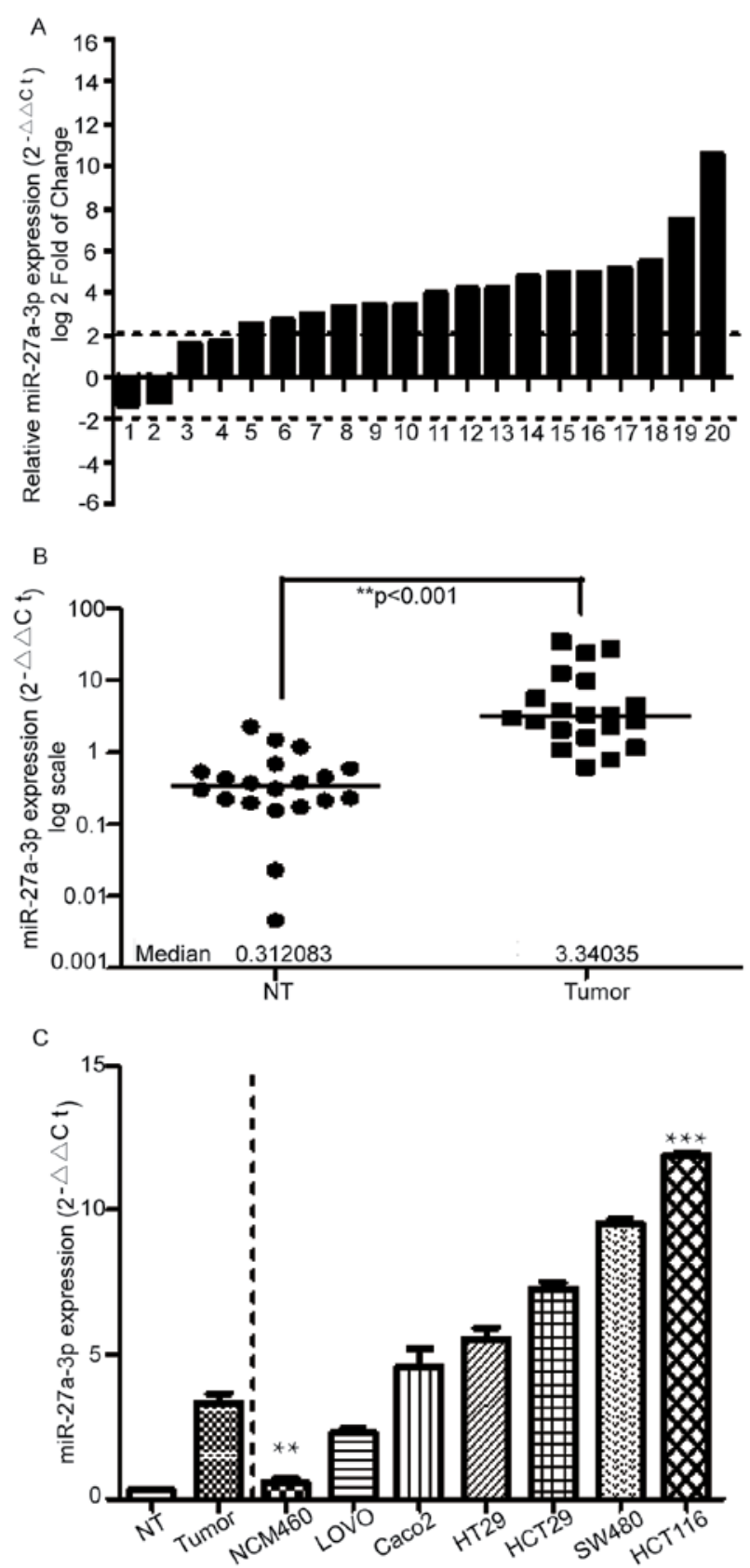

Figure 1. miR-27a-3p is overexpressed in colorectal cancer tissues and cell lines. (A) miR-27a-3p expression in 20 pairs of colorectal cancer and paired NT tissues determined as miR-27a-3p/U6 expression ratio. The $x$-axis displays case numbers. (B) Comparison of miR-27a-3p expression levels between colorectal cancer tissues and matched NT tissues according to quantitative PCR. Statistical analysis was performed using a Kruskal-Wallis test. (C) miR-27a-3p expression in the NT and tumor samples, colorectal epithelial NCM460 cells and human colon cancer cell lines HCT-116, HCT8, SW480, HT29, LOVO and Caco2. ${ }^{* *} \mathrm{P}<0.01,{ }^{* * *} \mathrm{P}<0.001$ vs. tumor. miR-27a-3p, microRNA-27a-3p; NT, non-tumorous.

normal colorectal cell line NCM460 (Fig. 1C). Overall, these data indicated that expression of miR-27a-3p was increased in CRC tissues and colon cancer cell lines.

miR-27a-3p promotes colon cancer cell proliferation. To evaluate the role of miR-27a-3p in colon cancer cells, the miR-27a overexpression vector pEGFP-C1-miR-27a (+) was established by inserting a miR-27a precursor containing flanking 

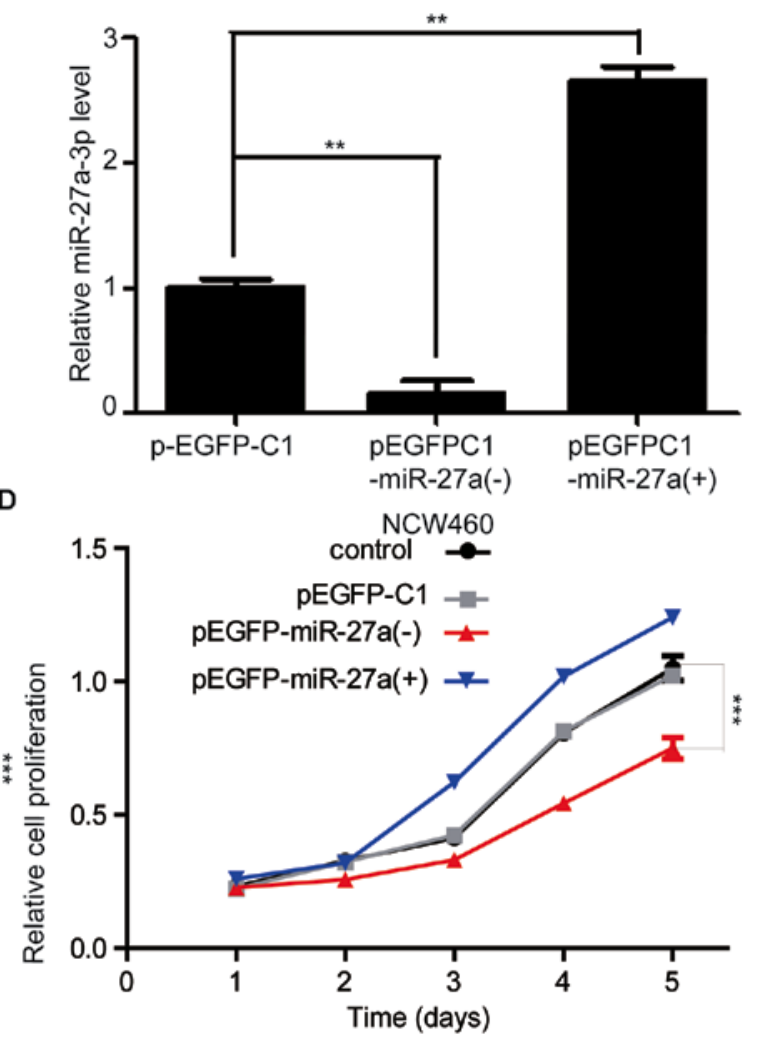

NCM460
A

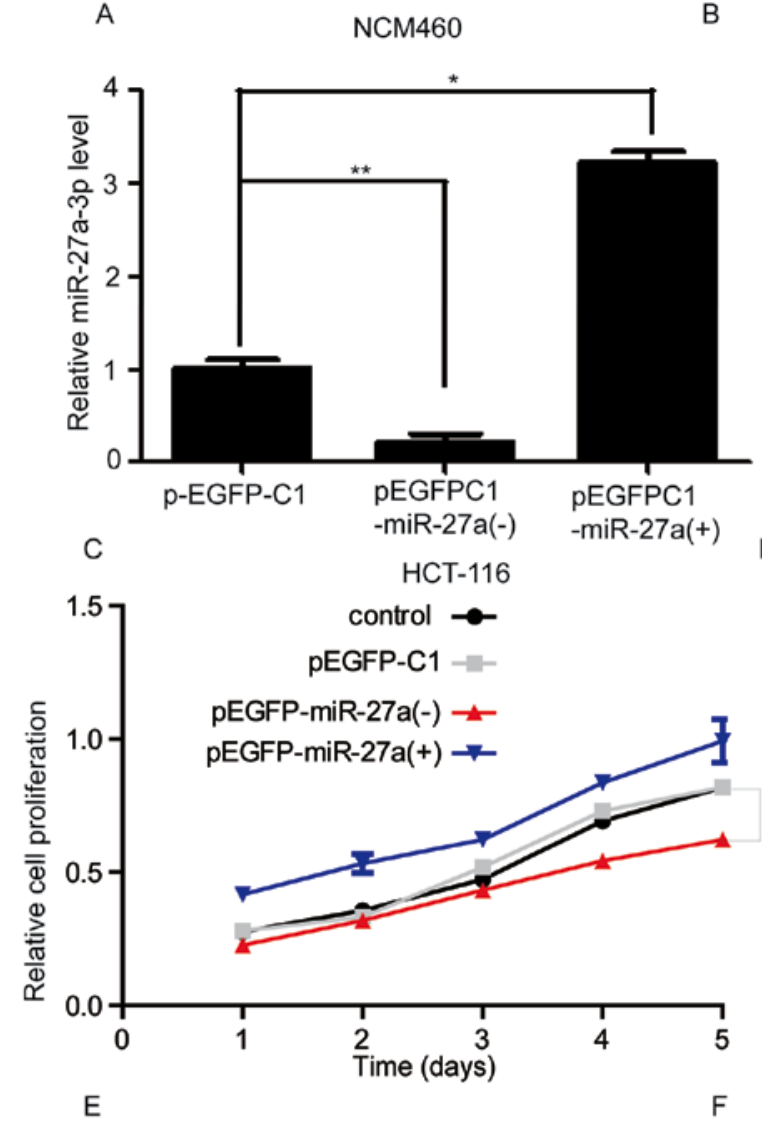

HCT116

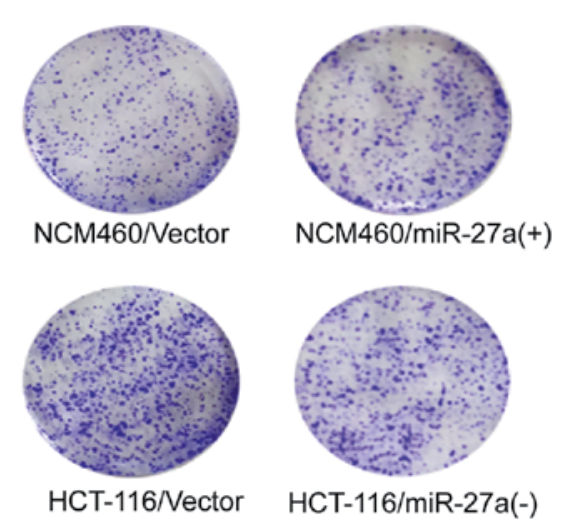

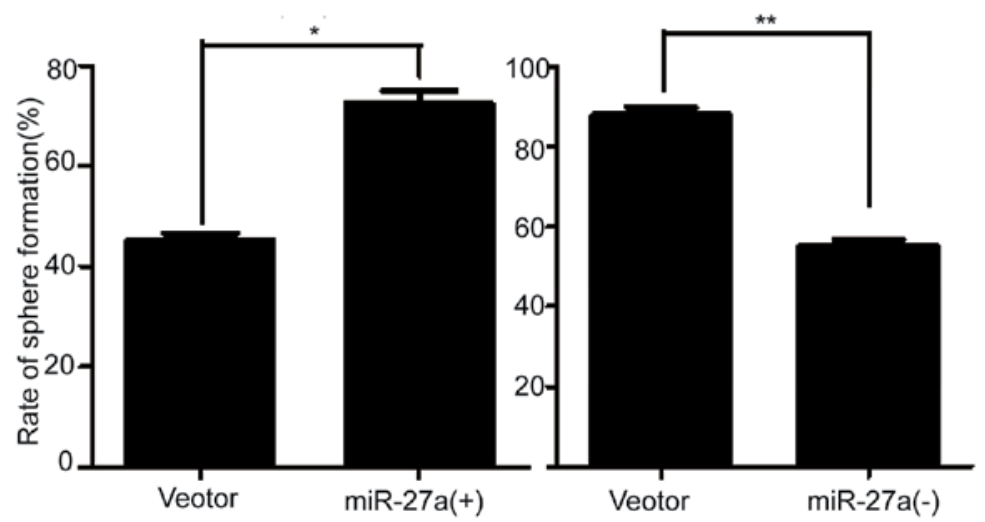

Figure 2. miR-27-3a affects the proliferation and colony formation ability of colon cancer cells. Transfection efficiency in (A) NCM460 and (B) HCT-116 cells for pEGFP-C1-miR-27a (+) and pEGFP-C1-miR-27a (-) compared with the empty plasmid. (C) Growth curves of HCT-116 cells transfected with pEGFP-C1, pEGFP-C1-miR-27a (+) or pEGFP-C1-miR-27a (-). (D) Growth curves of NCM460 cells transfected with pEGFP-C1, pEGFP-C1-miR-27a (+) or pEGFP-C1-miR-27a (-). (E) Clone formation assay of NCM460 and HCT-116 cells transfected with miR-27a (+/-)/pEGFP-C1, respectively or pEGFP-C1. The number of microspheres was counted after 2 weeks. (F) Quantification of the clone formation assay comparing miR-27a-3p (+) or (-) with the empty vector in HCT-116 cells. Statistical analysis was performed using an ANOVA. All data are presented as the mean \pm SD and are representative of three measurements. ${ }^{*} \mathrm{P}<0.05 ;{ }^{* * *} \mathrm{P}<0.01 ;{ }^{* * *} \mathrm{P}<0.001$ vs. control. (+), mimic; (-), inhibitor; miR-27a, microRNA-27a-3p.

sequences into the pEGFP-C1 vector. Subsequently, the miR-27a expression vector or a competitive inhibitor plasmid, pEGFP-C1-miR-27a (-), were transfected into HCT-116 and NCM460 cells. RT-qPCR was used to verify the transfection efficiency. Results revealed that in pEGFP-C1-miR-27a (+) transfected cells, expression of miR-27a-3p was significantly upregulated, while in pEGFP-C1-miR-27a (-) transfected cells it was significantly decreased compared with the pEGFP-C1 transfected cells (Fig. 2A and B). The results of cell proliferation assays indicated that inhibiting miR-27a-3p expression reduced the growth rate of HCT-116 cells, whereas miR-27a-3p overexpression had no obvious effect on cell proliferation (Fig. 2C). Additionally, cell proliferation assays were used to detect the effect on NCW460 cells. It was revealed that miR-27a-3p overexpression promoted cell proliferation, although this effect was not observed to be statistically significant, while inhibiting miR-27a-3p expression had a significant effect on cell proliferation (Fig. 2D). Clone formation assays revealed the effect of inhibiting miR-27a-3p expression to inhibit the growth in HCT-116 cells and overexpression of miR-27a-3p could promote the growth of NCM460 cells (Fig. 2E and F). Since miR-27a-3p was overexpressed in CRC 
A

$\begin{array}{cc}\text { BTG1 mRNA } & \text { UAAACCAUGUCACAGCUGUGAAG } \\ & 106 \quad \text { I }||||||^{112} \\ \text { miR-27a-3p } & \text { CGCCUUGAAUCGGUGACACUU }\end{array}$

C

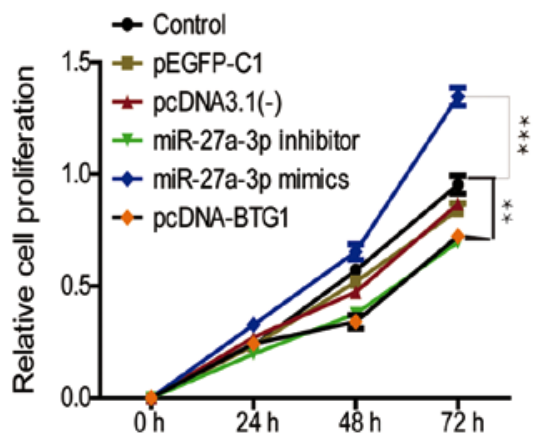

E

Control

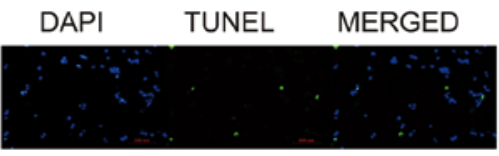

miR-27a-3p inhibitor

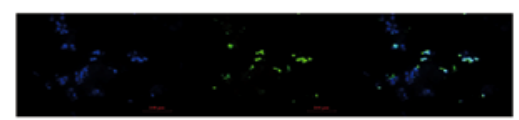

miR-27a-3p mimics

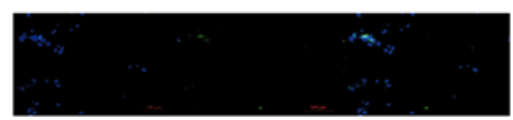

pcDNA-BTG1

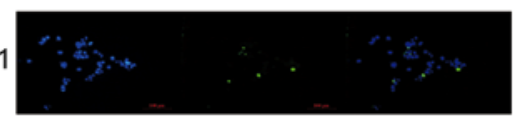

G

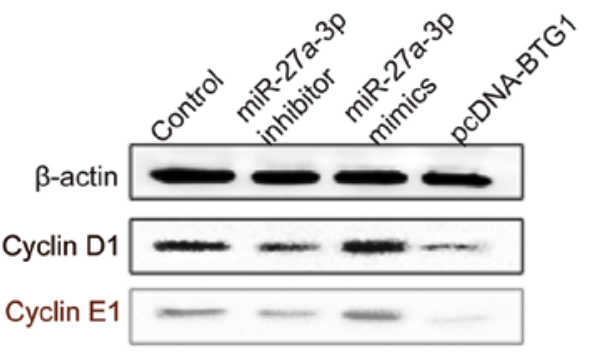

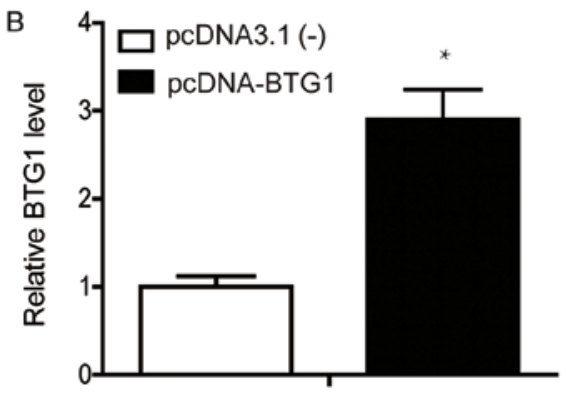

D

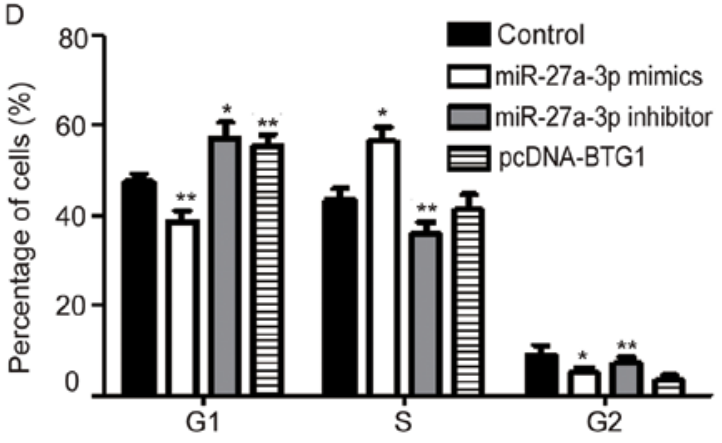

$\mathrm{F}$

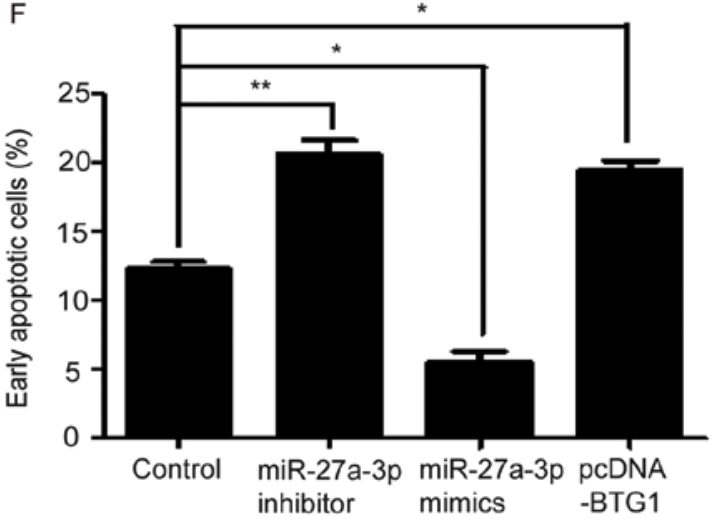

$\mathrm{H}$

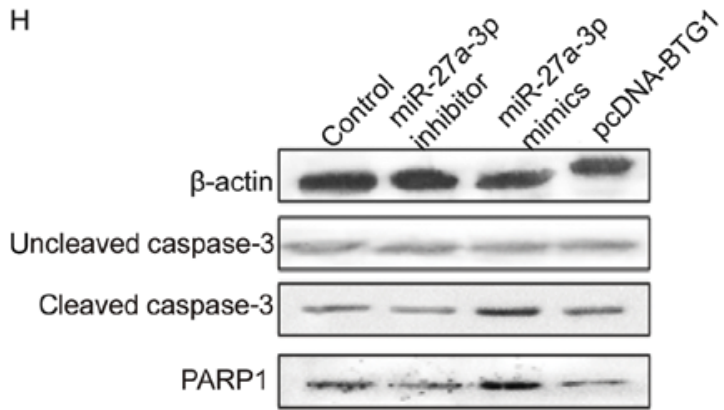

Figure 3. miR-27a-3p and BTG1 regulate cell cycle progression and apoptosis in colon cancer cells. (A) Binding between miR-27-3p and BTG1 as determined by the target prediction programs. (B) BTG1 mRNA expression based on reverse transcription-quantitative PCR analysis for cells transfected with pcDNA-BTG1 or empty vector. (C) MTT assays following transfection with miR-27a-3p inhibitor/mimics or pcDNA-BTG1; the growth rates were compared to the untreated control group. (D) Flow cytometry based cell cycle analysis following transfection with miR-27a-3p inhibitor/mimic or pcDNA-BTG1; results are compared with the untreated control group. (E) TUNEL staining images for HCT-116 cells transfected with miR-27a-3p inhibitor/mimic or pcDNA-BTG1 (magnification, x20). Blue represents DAPI and green represents protein apoptosis. (F) Flow cytometry was performed to determine the rates of apoptosis of the different transfection groups., Statistical analysis was performed using ANOVA. All data are presented as the mean $\pm \mathrm{SD}$, and are representative of an average of three measurements. ${ }^{*} \mathrm{P}<0.05,{ }^{* * *} \mathrm{P}<0.01$ vs. control. Western blotting was performed to determine the levels of $(\mathrm{G})$ the cell cycle-associated proteins cyclin D and cyclin E and $(\mathrm{H})$ the apoptosis-associated proteins caspase 3 and PARP1 in the transfected cells; $\beta$-actin was used as loading control. ${ }^{* *} \mathrm{P}<0.01$; ${ }^{* * * *} \mathrm{P}<0.001$. BTG1, B-cell translocation gene 1; miR-27a-3p, microRNA-27a-3p; PARP1, poly(ADP-ribose) polymerase 1.

tissues and cells, it could promote the proliferation of cancer cells. The MTT assay revealed that miR-27a-3p overexpression could promote the proliferation of NCW460 cells, indicating that overexpression of miR-27a-3p could promote the proliferation of normal cells and cancer cells. Inhibiting miR-27a-3p expression could reduce the proliferation of HCT-116 cells. 
The role of miR-27a-3p in normal and cancer cells was investigated by overexpression and knockdown, respectively. Since miR-27a-3p overexpression had no effect on the growth of HCT-116 cells in the MTT assay, inhibition of miR-27a-3p also had no effect on the NCM460 cells in the MTT assay. Therefore, the clone formation assay with significant influence was selected.

miR-27a-3p and BTG1 regulate cell cycle progression and apoptosis in colon cancer cells. It has been reported that BTG1 acts as a tumor suppressor in several human malignant tumors, including CRC (38). It is also known to be a gene that induces apoptosis and inhibits proliferation (23). In order to improve the understanding of the functional mechanism of miR-27a-3p in colorectal tumorigenesis, direct targets of miR-27a-3p that may have biological functions need to be identified. Therefore, possible targets of miR-27a-3p were predicted using the target prediction programs TargetMiner (41), miRbase, PicTar (40) and TargetScan (42). BTG1, which is involved in cell proliferation, was indicated to be associated with the biological function of miR-27a-3p among hundreds of potential candidates, since its 3 -untranslated region contains a putative target sequence for miR-27a-3p (Fig. 3A). Transfection efficiency for the BTG1 overexpression system was determined by RT-qPCR illustrating that BTG1 expression was significantly increased compared with the empty vector (Fig. 3B). To further investigate the effects of miR-27a-3p and BTG1 on HCT-116 cells, miR-27a-3p inhibitor/mimics or BTG1 plasmid were transfected into the cells to regulate the respective expression. In MTT assays at 48 and $72 \mathrm{~h}, \mathrm{miR}-27 \mathrm{a}-3 \mathrm{p}$ inhibitor and BTG1 markedly suppressed the proliferation of HCT-116 cells. There was no difference identified between the vector pEGFP-C1, pcDNA3.1(-) and control groups in terms of cell growth. The miR-27a-3p mimics significantly promoted cells growth compared with the control group (Fig. 3C). Additionally, following transfection with miR-27a-3p inhibitor or BTG1, the proportion of cells in the $G_{1}$ phase increased. miR-27a-3p mimic transfection had the opposite effects (Fig. 3D). Transfection with miR-27a-3p inhibitor or pcDNA-BTG1 significantly induced apoptosis in HCT-116 cells and miR-27a-3p mimics had the opposite effect (Fig. 3E and $\mathrm{F}$ ). Fig. $3 \mathrm{G}$ and $\mathrm{H}$ shows the results of the western blotting analysis of cell cycle and apoptosis-associated proteins. The present study identified a negative association between cyclin D1 and cyclin E1 and BTG1. BTG1, similar to the miR-27a-3p inhibitor, could reduce the protein expression of cyclin D1 and cyclin E1 (Fig. 3G). Overexpression of miR-27a-3p could increase cyclin D1 and cyclin E1 expression. Similarly, BTG1 overexpression and miR-27a-3p inhibition increased the percentage of cells in $G_{1}$ phase, and miR-27a-3p mimics decreased the percentage of cells in $G_{1}$ phase (Fig. 3D). The protein expression levels of cleaved-caspase 3 were observed in miR-27a-3p inhibitor/mimics or BTG1 plasmid treated HCT-116 cells (Fig. 3H), levels of cleaved-caspase 3 were higher in HCT-116 cells treated with miR-27a-3p mimic compared with the untreated control cells. Collectively, these results indicated that inhibition of miR-27a-3p or overexpression of BTG1 reduced proliferation and promoted apoptosis in HCT-116 cells.

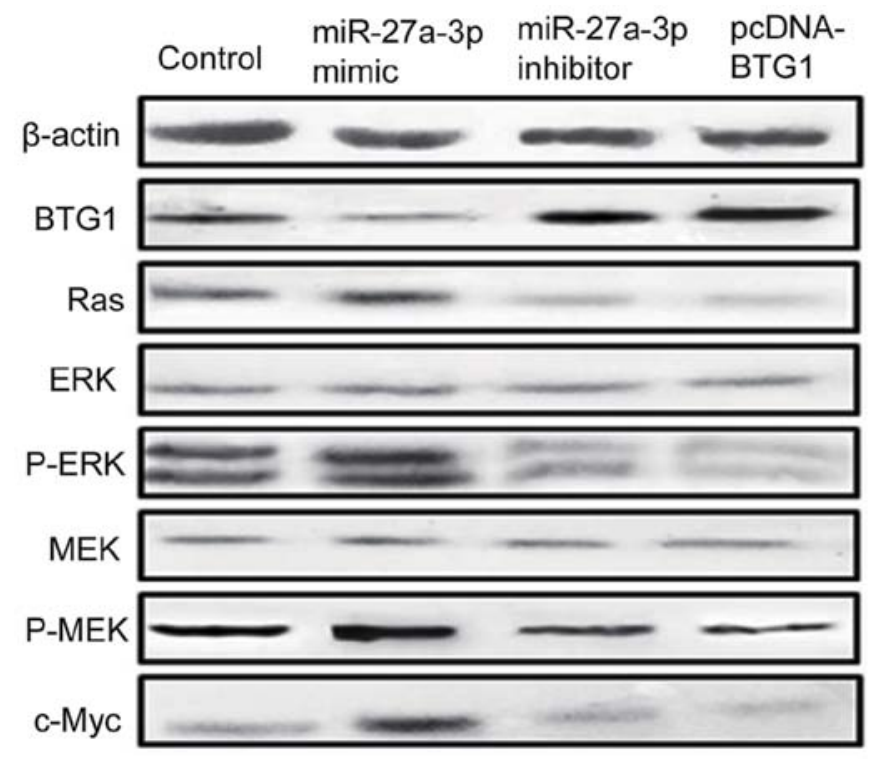

Figure 4. miR-27a-3p inhibits c-Myc expression by targeting the RAS/MEK/ERK signaling pathway in HCT-116 cells. Western blotting was performed to determine the protein levels of BTG1, Ras, MEK, p-MEK-1, ERK, P-ERK and c-Myc; $\beta$-actin was used as loading control. BTG1, B-cell translocation gene 1; MEK, mitogen-activated extracellular signal-regulated kinase; miR-27a-3p, microRNA 27a-3; P-, phospho-.

miR-27a-3p affects cell proliferation and apoptosis via the ERK/MEK signaling pathway. In order to further investigate how miR-27a-3p affected cell proliferation and apoptosis, the downstream signaling pathway mediated by BTG1 was studied. A previous study demonstrated that the ERK/MEK signaling pathway is a downstream pathway of BTG2 in gastric carcinoma (15). This was verified by western blot analysis in the present study. The results revealed that inhibition of miR-27a-3p and overexpression of BTG1 decreased the levels of p-ERK and p-MEK-1 but had no effect on ERK or MEK expression. Inhibition of miR-27a-3p and overexpression of BTG1 could increase BTG1 expression but decreased Ras and c-Myc expression (Fig. 4).

\section{Discussion}

CRC, a type of malignant tumor, is the second leading cause of cancer-associated mortality in Asia (43). It is also the third most commonly diagnosed type of cancer in men and the second in women worldwide (44). Despite advances in treatment modalities, the prognosis for patients with CRC has not significantly improved (45). miR-27a-3p (has-miR-27a-3p) has been identified as an onco-miRNA in several solid tumors, including breast (46), ovarian (47), pancreatic (48) and gastric (16) cancer. miR-27a has also been reported to be a key oncogenic component in CRC and miR-27a is overexpressed in CRC (49). miR-27a-3p may accelerate tumorigenesis by targeting several tumor suppressors, including BTG2 (15), F-box and WD repeat domain containing 7 (19), Yes associated protein 1 (50) and Wnt family member 3A (51). Regarding BTG1, it has been reported that the tumor suppressor enhances Hoxb9-mediated transcription and inhibits HeLa cell proliferation (52). Overexpression of BTG1 has been detected in apoptotic cells exhibiting DNA fragmentation and nuclear 
condensation (53). Additionally, expression levels of BTG1 are decreased in kidney cancer and are associated with poor prognosis (54).

Our previous study (15) confirmed that overexpression of miR-27a-3p promoted gastric cancer cell proliferation in vitro as well as tumor growth in vivo and that BTG2 was a direct target of miR-27a-3p in gastric cancer. Zhao et al (35) reported that BTG1 overexpression suppresses proliferation and cell cycle progression, and induces apoptosis, autophagy and differentiation in CRC cells. Therefore, the present study aimed to examine the effects of miR-27a-3p in CRC and verify BTG1 as a putative target of miR-27a-3p. The findings of the present study revealed that miR-27a-3p served as an oncogene in CRC. The expression levels of miR-27a-3p were significantly increased in CRC tissues compared with in the paired non-tumor tissues, and miR-27a-3p overexpression promoted the proliferation of HCT-116 cells. Furthermore, in cell proliferation experiments, the empty vectors had no effect on cell proliferation. miR-27a-3p mimic could reduce the proportion of cells in $\mathrm{G}_{1}$ phase. Additionally, transfection with miR-27a-3p mimic induced early apoptosis in HCT-116 cells.

Cyclin E and D activate cyclin dependent kinases (CDKs) during the cell cycle and serve an important regulatory role in the transition between $\mathrm{G}_{1}$ and $\mathrm{S}$ phases. Increased $\mathrm{p} 21$ and p27 binding to cyclin and CDKs results in $\mathrm{G}_{1}$ arrest (55). Cyclin B1-CDK1 is involved in the early events of mitosis, and $\mathrm{CDC} 25 \mathrm{~B}$ activates $\mathrm{CDC} 2$ to initiate mitosis (56). In the present study, increased expression of miR-27a-3p was indicated to result in a lowered ratio of HCT-116 cells in the $\mathrm{G}_{1}$ phase. Additionally, the protein expression levels of cyclin E1 and D1 were evaluated.

Zhao et al (35), assessed levels of apoptosis regulators, including Bcl-2, Bcl-xL, Bax, survivin, X-linked inhibitor of apoptosis, Akt1 and tumor suppressor p53 in HCT-15 cells overexpressing BTG1. Overexpression of BTG1 decreases Bcl-2 and Bax protein levels and upregulates p53 expression in the human esophageal cancer cell line ECA-109 (57), human thyroid cancer cell line FTC-133 (58), human breast tumors and breast cancer cells (MCF-7 and MDA-MB-231) (24), ovarian carcinoma cells OVCAR3 (59) and hematological malignancies cells (60). Furthermore, overexpression of BTG1 induces apoptosis of HCT-15 and HCT-116 cells, and decreases mitochondrial potential and increases senescence only in HCT-116 cells, suggesting differences in the mechanisms of apoptosis in these two cell lines (35). The induction of cell death requires activation of one or more members of the well-conserved caspases, a family of cysteinyl proteases $(61,62)$. Following proteolytic activation from their proenzyme forms, caspases cleave various protein substrates, including lamins and PARP (63). PARP-1 is a member of the PARP family that is involved in differentiation, proliferation and tumor transformation (64). The present study investigated how the expression of miR-27a-3p affected colon cancer cell apoptosis. The current study suggested that BTG1 was a downstream target of miR-27a-3p. Different from previous studies, the present study investigated the effects of miR-27a-3p on proliferation and apoptosis of CRC cells by BTG1 overexpression. Transfection of HCT-116 cells with miR-27a-3p mimics revealed the decrease of BTG1 expression and the elevation of cleaved-caspase 3 and PARP1 protein expression. The downregulated expression of apoptosis-associated genes and their encoded proteins may be the molecular basis of the difference in the apoptotic mechanism of BTG1-overexpressing cancer cells. To confirm this, the mechanism of BTG1-induced apoptosis will be investigated in future studies.

In human cancers, aberrant activation of the RAF/MEK/ ERK signaling pathway is frequently observed. There has been increasing evidence revealing the importance of the RAF/MEK/ERK signaling pathway in tumorigenesis (65-67). The relatively high frequency of activating mutations of RAS ( $20 \%$ of all human types of cancer), an upstream activator of the well-established RAF/MEK/ERK signaling cascade, as well as frequent activating mutations in the BRAF kinase gene ( $7 \%$ of all human types of cancer) have been observed (68). Therefore, RAF and MEK kinases have received great attention among the numerous kinases $(69,70)$.

miRNAs perform biological functions by suppressing their target genes (71). To explore the functional mechanism of miR-27a-3p in CRC, TargetMiner, miRBase, PicTar and TargetScan were used to predict possible targets of miR-27a-3p. From various potential candidates, BTG1 was selected, since it is accepted as a tumor suppressor and closely involved in cell proliferation $(70,72)$. The present study revealed that transfection with miR-27a-3p inhibitor markedly upregulated the protein expression of BTG1 in HCT-116 cells, while transfection with miR-27a-3p mimic had the opposite effect. The present study also demonstrated that transfection with BTG1 had similar effects as transfection with the miR-27a-3p inhibitor, causing cell cycle arrest at $\mathrm{G}_{1}$ phase and inducing apoptosis in HCT-116 cells. Furthermore, inhibition of miR-27a-3p and overexpression of BTG1 decreased the level of p-ERK and p-MEK-1 in HCT-116 cells. All these results indicated that BTG1 may be a novel target of miR-27a-3p and may serve a tumor suppressor role in CRC. These findings may provide novel insights into the mechanisms underlying CRC and have potential applications in diagnosis and therapy.

In conclusion, the present study showed that downregulation of miR-27a-3p significantly inhibited proliferation and enhanced apoptosis in HCT-116 cells. miR-27a-3p may serve an important role in CRC cells by directly targeting BTG1.

\section{Acknowledgements}

Not applicable.

\section{Funding}

The present study was supported by the Natural Science Research Project of Minhang District (grant no. 2017MHZ75).

\section{Availability of data and materials}

The datasets used and/or analyzed during the present study are available from the corresponding author on reasonable request.

\section{Authors' contributions}

CS and YOC designed the study and prepared the figures. DPH and WYL collated the data and carried out data analyses. JWL drafted the manuscript and revised it critically for 
important intellectual content, in addition they contributed to the interpretation of data. All authors read and approved the final manuscript.

\section{Ethics approval and consent to participate}

The study was approved by the Associated Institutional Review Board of Minhang Branch, Zhongshan Hospital, Fudan University and signed informed consent was obtained from all participants.

\section{Patient consent for publication}

Not applicable.

\section{Competing interests}

The authors declare that they have no competing interests.

\section{References}

1. Cunningham D, Atkin W, Lenz HJ, Lynch HT, Minsky B, Nordlinger B and Starling N: Colorectal cancer. Lancet 375: $1030-1047,2010$

2. Torre LA, Bray F, Siegel RL, Ferlay J, Lortet-Tieulent J and Jemal A: Global cancer statistics. 2012. CA Cancer J Clin 65 : 87, 2015.

3. Zhang Y, Shi J, Huang H, Ren J, Li N and Dai M: Burden of colorectal cancer in China. Zhonghua Liu Xing Bing Xue Za Zhi 36: 709-714, 2015 (In Chinese).

4. Carrie P: Declines in death from colorectal cancer in europe deemed major success. Cancer 124: 2876-2876, 2018.

5. Al-Sukhni E. and Gallinger S: Treatment of colorectal cancer. Springer Netherlands, p809-812, 2010.

6. Coppedè F, Lopomo A, Spisni R and Migliore L: Genetic and epigenetic biomarkers for diagnosis, prognosis and treatment of colorectal cancer. World J Gastroenterol 20: 943-956, 2014.

7. Ciombor $\mathrm{KK}, \mathrm{Wu} \mathrm{C}$ and Goldberg RM: Recent therapeutic advances in the treatment of colorectal cancer. Annu Rev Med 66: 83-95, 2014.

8. Ju J: miRNAs as biomarkers in colorectal cancer diagnosis and prognosis. Bioanalysis 2: 901-906, 2010.

9. Chen X, Shi K, Wang Y, Song M, Zhou W, Tu H and Lin Z: Clinical value of integrated-signature miRNAs in colorectal cancer: miRNA expression profiling analysis and experimental validation. Oncotarget 6: 37544-37556, 2015

10. Yang Q, Jie Z, Ye S, Li Z, Han Z, Wu J, Yang C and Jiang Y: Genetic variations in miR-27a gene decrease mature miR-27a level and reduce gastric cancer susceptibility. Oncogene 33: 193-202, 2014.

11. Calin GA, Sevignani C, Dumitru CD, Hyslop T, Noch E, Yendamuri S, Shimizu M, Rattan S, Bullrich F, Negrini M and Croce CM: Human microRNA genes are frequently located at fragile sites and genomic regions involved in cancers. Proc Natl Acad Sci USA 10: 2999-3004, 2004.

12. Lu J, Getz G, Miska EA, Alvarez-Saavedra E, Lamb J, Peck D, Sweet-Cordero A, Ebert BL, Mak RH, Ferrando AA, et al: MicroRNA expression profiles classify human cancers. Nature 43: 834-838, 2005.

13. Calin GA and Croce CM: MicroRNA signatures in human cancers. Nat Rev Cancer 6: 857-866, 2006.

14. Calin GA and Croce CM: MicroRNA-cancer connection: The beginning of a new tale. Cancer Res 66: 7390-7394, 2006.

15. Zhou L, Liang X, Zhang L, Yang L, Nagao N, Wu H, Liu C, Lin S, Cai G and Liu J: MiR-27a-3p functions as an oncogene in gastric cancer by targeting BTG2. Oncotarget 7: 51943-51954, 2016.

16. Liu T, Tang H, Lang Y, Liu M and Li X: MicroRNA-27a functions as an oncogene in gastric adenocarcinoma by targeting prohibitin. Cancer Lett 273: 233-242, 2009.

17. Xu W, Liu M, Peng X, Zhou P, Zhou J, Xu K, Xu H and Jiang S: miR-24-3p and miR-27a-3p promote cell proliferation in glioma cells via cooperative regulation of MXI1. Int J Oncol 42: 757-766, 2013.
18. Zhao N, Sun H, Sun B, Zhu D, Zhao X, Wang Y, Gu Q, Dong X, Liu F, Zhang Y and Li X: miR-27a-3p suppresses tumor metastasis and VM by down-regulating VE-cadherin expression and inhibiting EMT: An essential role for Twist-1 in HCC. Sci Rep 6: 23091, 2016.

19. Wu XZ, Wang KP, Song HJ, Xia JH, Jiang Y and Wang YL: MiR-27a-3p promotes esophageal cancer cell proliferation via F-box and WD repeat domain-containing 7 (FBXW7) suppression. Int J Clin Exp Med 8: 15556-15562, 2015.

20. Nakata W, Uemura M, Sato M, Fujita K, Jingushi K, Ueda Y, Kitae K, Tsujikawa K and Nonomura N: Expression of miR-27a-3p is an independent predictive factor for recurrence in clear cell renal cell carcinoma. Oncotarget 6: 21645-21654, 2015.

21. Li L and Luo Z: Dysregulated miR-27a-3p promotes nasopharyngeal carcinoma cell proliferation and migration by targeting Mapk10. Oncol Rep 37: 2679-2687, 2017.

22. Winkler GS: The mammalian anti-proliferative BTG/Tob protein family. J Cell Physiol 222: 66-72, 2010.

23. Sasajima H, Nakagawa $\mathrm{K}$ and Yokosawa $\mathrm{H}$ : Antiproliferative proteins of the BTG/Tob family are degraded by the ubiquitin-proteasome system. Eur J Biochem 269: 3596-3604, 2002.

24. Zhu R, Zou ST, Wan JM, Li W, Li XL and Zhu W: BTG1 inhibits breast cancer cell growth through induction of cell cycle arrest and apoptosis. Oncol Rep 30: 2137-2144, 2013.

25. Liu C, Tao T, Xu B, Lu K, Zhang L, Jiang L, Chen S, Liu D, Zhang X, Cao N and Chen M: BTG1 potentiates apoptosis and suppresses proliferation in renal cell carcinoma by interacting with PRMT1. Oncol Lett 10: 619-624, 2015.

26. He C, Yu T, Shi Y, Ma C, Yang W, Fang L, Sun M, Wu W, Xiao F, Guo F, et al: MicroRNA 301A promotes intestinal inflammation and colitis-associated cancer development by inhibiting BTG1. Gastroenterology 152: 1434-1448, 2017

27. Lee AS, Kranzusch PJ and Cate JH: eIF3 targets cell-proliferation messenger RNAs for translational activation or repression. Nature 522: 111-114, 2015.

28. Waanders E, Scheijen B, van der Meer LT, van Reijmersdal SV, van Emst L, Kroeze Y, Sonneveld E, Hoogerbrugge PM, van Kessel AG, van Leeuwen FN and Kuiper RP: The origin and nature of tightly clustered BTG1 deletions in precursor B-cell acute lymphoblastic leukemia support a model of multiclonal evolution. PLoS Genet 8: e1002533, 2012.

29. Rouault JP, Rimokh R, Tessa C, Paranhos G Ffrench M, Duret L, Garoccio M, Germain D, Samarut J and Magaud JP: BTG1, a member of a new family of antiproliferative genes. Embo J 11: 1663-1670, 1992

30. Corjay MH, Kearney MA, Munzer DA, Diamond SM and Stoltenborg JK: Antiproliferative gene BTG1 is highly expressed in apoptotic cells in macrophage-rich areas of advanced lesions in Watanabe heritable hyperlipidemic rabbit and human. Lab Invest 78: 47-58, 1998 .

31. Nahta R, Yuan LX, Fiterman DJ, Zhang L, Symmans WF, Ueno NT and Esteva FJ: B cell translocation gene 1 contributes to antisense $\mathrm{Bcl}-2$-mediated apoptosis in breast cancer cells. Mol Cancer Ther 5: 93-60, 2006.

32. Li Y, Choi PS, Casey SC, Dill DL and Felsher DW: MYC through miR-17-92 suppresses specific target genes to maintain survival, autonomous proliferation, and a neoplastic state. Cancer Cell 26: $62-72,2014$

33. Zheng HC, Li J, Shen DF, Yang XF, Zhao S, Wu YZ, Takano Y, Sun HZ, Su RJ, Luo JS and Gou WF: BTG1 expression correlates with pathogenesis, aggressive behaviors and prognosis of gastric cancer: A potential target for gene therapy. Oncotarget 19: 685-705, 2015.

34. Williams G and Stoeber K: The cell cycle and cancer. J Pathol 226: 352-364, 2012.

35. Zhao S, Chen SR, Yang XF, Shen DF, Takano Y, Su RJ and Zheng HC: BTG1 might be employed as a biomarker for carcinogenesis and a target for gene therapy in colorectal cancers. Oncotarget 8: 7502-7520, 2017.

36. Shen K, Liang Q, Xu K, Cui D, Jiang L, Yin P, Lu Y, Li Q and Liu J: MiR-139 inhibits invasion and metastasis of colorectal cancer by targeting the type I insulin-like growth factor receptor. Biochem Pharmacol 84: 320-330, 2012.

37. Zou F, Mao R, Yang L, Lin S, Lei K, Zheng Y, Ding Y, Zhang P, Cai G, Liang $X$ and Liu J: Targeted deletion of miR-139-5p activates MAPK, NF- $\kappa \mathrm{B}$ and STAT3 signaling and promotes intestinal inflammation and colorectal cancer. FEBS J 283: $1438-1452,2016$ 
38. Bai Y, Qiao L, Xie N, Shi Y, Liu N and Wang J: Expression and prognosis analyses of the Tob/BTG antiproliferative (APRO) protein family in human cancers. PLoS One 12: e0184902, 2017.

39. Livak KJ and Schmittgen TD: Analysis of relative gene expression data using real-time quantitative PCR and the 2(-Delta Delta C(T)) method. Methods 25: 402-408, 2001.

40. Krek A, Grün D, Poy MN, Wolf R, Rosenberg L, Epstein EJ, MacMenamin P, da Piedade I, Gunsalus KC, Stoffel M and Rajewsky N: Combinatorial microRNA target predictions. Nat Genet 37: 495-500, 2005.

41. Bandyopadhyay S and Mitra R: TargetMiner: microRNA target prediction with systematic identification of tissue-specific negative examples. Bioinformatics 25: 2625-2631, 2009.

42. Xu W, San Lucas A, Wang Z and Liu Y: Identifying microRNA targets in different gene regions. BMC Bioinformatics 15 (Suppl 7): S4, 2014

43. Ferrer RR, Ramirez M, Beckman LJ, Danao LL and Ashing-Giwa KT: The impact of cultural characteristics on colorectal cancer screening adherence among Filipinos in the United States: A pilot study. Psychooncology 20: 862-870, 2011.

44. Weitz J, Koch M, Debus J, Höhler T, Galle PR and Büchler MW: Colorectal cancer. Lancet 365: 1066-1066, 2005.

45. Wolpin BM and Mayer RJ: Systemic treatment of colorectal cancer. Gastroenterology 134: 1296-1310, 2008.

46. Zhou S, Huang Q, Zheng S, Lin K, You J and Zhang X: miR-27a regulates the sensitivity of breast cancer cells to cisplatin treatment via BAK-SMAC/DIABLO-XIAP axis. Tumour Biol 37: 6837-6845, 2016.

47. Lin-Lin XU, et al: Effects of genistein on the growth of ovarian cancer cell SKOV3 by regulating miR-27a and target gene expression. Chin J Clin Pharmacol Ther 17: 1321-1326, 2012 (In Chinese).

48. Ma Y, Yu S, Zhao W, Lu Z and Chen J: miR-27a regulates the growth, colony formation and migration of pancreatic cancer cells by targeting Sprouty2. Cancer Lett 298: 150-158, 2010.

49. Choo KB, Soon YL, Nguyen PN, Hiew MS and Huang CJ: MicroRNA-5p and $-3 p$ co-expression and cross-targeting in colon cancer cells. J Biomed Sci 21: 95, 2014.

50. Zeng G, Xun W, Wei K, Yang Y and Shen H: MicroRNA-27a-3p regulates epithelial to mesenchymal transition via targeting YAP1 in oral squamous cell carcinoma cells. Oncol Rep 36: 1475-1482, 2016.

51. Zhao Y, Wang P, Meng J, Ji Y, Xu D, Chen T, Fan R, Yu X, Yao J and Dong C: MicroRNA-27a-3p inhibits melanogenesis in mouse skin melanocytes by targeting Wnt3a. Int J Mol Sci 16: 10921-10933, 2015.

52. Prévôt D, Voeltzel T, Birot AM, Morel AP, Rostan MC, Magaud JP and Corbo L: The Leukemia-associated Protein Btg1 and the p53-regulated Protein Btg2 Interact with the Homeoprotein Hoxb9 and enhance its transcriptional activation. J Biol Chem 275: 147-153, 2000.

53. Corjay MH, Kearney MA, Munzer DA, Diamond SM and Stoltenborg JK: Antiproliferative gene BTG1 is highly expressed in apoptotic cells in macrophage-rich areas of advanced lesions in Watanabe heritable hyperlipidemic rabbit and human. Lab Invest 78: 847-858, 1998

54. Sun G, Liu Q, Cheng Y and Hu W: B cell translocation gene 1 reduces the biological outcome of kidney cancer through induction of cell proliferation, cell cycle arrest, cell apoptosis and cell metastasis. Int J Mol Med 35: 777-8348, 2015.

55. Bretones G, Delgado MD and León J: Myc and cell cycle control. Biochim Biophys Acta 1849: 506-516, 2015.

56. Sun GG, Wang YD, Cheng YJ and Hu WN: The expression of BTG1 is downregulated in nasopharyngeal carcinoma and possibly associated with tumour metastasis. Mol Biol Rep 41: 5979-5988, 2014
57. Sun GG, Wang YD, Cheng YJ and Hu WN: BTG1 underexpression is an independent prognostic marker in esophageal squamous cell carcinoma. Tumour Biol 35: 9707-9716, 2014.

58. Lu YF, Sun GG, Liu Q, Yang CR and Cheng YJ: BTG1 expression in thyroid carcinoma: Diagnostic indicator and prognostic marker. Int J Oncol 45: 1574-1582, 2014.

59. Zhao Y, Gou WF, Chen S, Takano Y and Zheng HC: BTG1 expression correlates with pathogenesis and progression of ovarian carcinomas. Int J Mol Sci 14: 19670-19680, 2013

60. Smolewski P and Robak T: Inhibitors of apoptosis proteins (IAPs) as potential molecular targets for therapy of hematological malignancies. Curr Mol Med 11: 633-649, 2011.

61. Nicholson DW and Thornberry NA: Trends Biochem. Sci 22: 299-306, 1997.

62. Salvesin GS and and Dixit VM: Caspases: Intracellular signaling by proteolysis. Cell 91: 443-446, 1997.

63. Shin S, Sung BJ, Cho YS, Kim HJ, Ha NC, Hwang JI, Chung CW, Jung $\mathrm{YK}$ and $\mathrm{Oh} \mathrm{BH}$ : An anti apoptotic protein human survivin is a direct inhibitor of caspase-3 and -7. Biochemistry 40: 1117-1123, 2001.

64. Nossa CW, Jain P, Tamilselvam B, Gupta VR, Chen LF, Schreiber V, Desnoyers S and Blanke SR: Activation of the abundant nuclear factor poly(ADP-ribose) polymerase-1 by Helicobacter pylori. Proc Natl Acad Sci USA 106: 19998-20003, 2009.

65. Li Y, Zhang Y, Xiao S, Kong P, Cheng C, Shi R, Wang F, Zhang L, Wang J, Jia Z, et al: Mps1 is associated with the BRAFV600E mutation but does not rely on the classic RAS/RAF/MEK/ERK signaling pathway in thyroid carcinoma. Oncol Lett 15: 9978-9986, 2018.

66. Cristea $S$ and Sage J: Is the Canonical RAF/MEK/ERK signaling pathway a therapeutic target in SCLC? J Thorac Oncol 11: 1233-1241, 2016.

67. ZhouK,LuoX,Wang Y,CaoDandSunG:MicroRNA-30asuppresses tumor progression by blocking Ras/Raf/MEK/ERK signaling pathway in hepatocellular carcinoma. Biomed Pharmacother 93 1025-1032, 2017.

68. Rapp UR, Goldsborough MD, Mark GE, Bonner TI, Groffen J, Reynolds FH Jr and Stephenson JR: Stephenson Structure and biological activity of v-raf, a unique oncogene transduced by a retrovirus Proc. Natl Acad Sci 80: 4218-4222, 1983.

69. Montagut C and Settleman J: Targeting the RAF-MEK-ERK pathway in cancer therapy. Cancer Lett 283: 125-134, 2009.

70. Steelman LS, Chappell WH, Abrams SL, Kempf RC, Long J, Laidler P, Mijatovic S, Maksimovic-Ivanic D, Stivala F, Mazzarino MC, et al: Roles of the Raf/MEK/ERK and $\mathrm{PI} 3 \mathrm{~K} / \mathrm{PTEN} / \mathrm{Akt} / \mathrm{mTOR}$ pathways in controlling growth and sensitivity to therapy-implications for cancer and aging. Aging (Albany NY) 3: 192-222, 2011.

71. Zhang H, Tang J, Li C, Kong J, Wang J, Wu Y, Xu E and Lai M: MiR-22 regulates 5-FU sensitivity by inhibiting autophagy and promoting apoptosis in colorectal cancer cells. Cancer Lett 356: 781-790, 2015.

72. Weng W, Liu N, Toiyama Y, Kusunoki M, Nagasaka T, Fujiwara T, Wei Q, Qin H, Lin H, Ma Y and Goel A: Novel evidence for a PIWI-interacting RNA (piRNA) as an oncogenic mediator of disease progression, and a potential prognostic biomarker in colorectal cancer. Mol Cancer 17: 16, 2018.

This work is licensed under a Creative Commons Attribution-NonCommercial-NoDerivatives 4.0 International (CC BY-NC-ND 4.0) License. 